Marcus K.M. Tso

\title{
Ethics in the Qumran Community
}

An Interdisciplinary Investigation

[Ethik in der Gemeinde von Qumran. Eine interdisziplinäre Studie.]

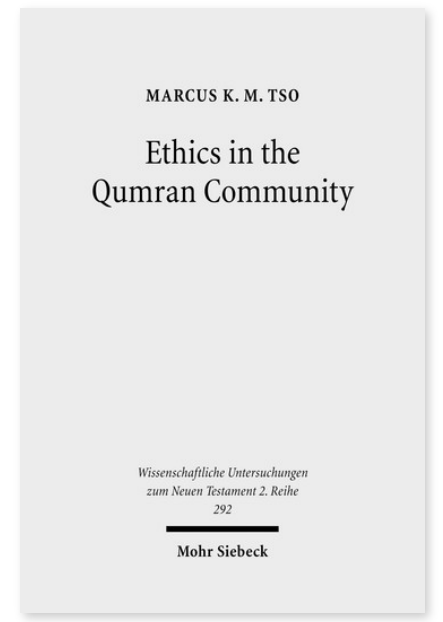

2010. XIV, 270 Seiten. WUNT II 292

ISBN 978-3-16-151635-1

DOI 10.1628/978-3-16-151635-1

eBook PDF 74,00€

ISBN 978-3-16-150618-5

fadengeheftete Broschur 74,00€
Veröffentlicht auf Englisch.

Unter Anwendung einer interdisziplinären Methode untersucht Marcus Tso im vorliegenden Buch ein lange vernachlässigtes Thema. Er analysiert die in Qumran gesammelten Texte im Hinblick auf die Grundlagen, also weniger auf den Inhalt der Ethik der örtlichen Gemeinde. Er vergleicht zunächst die ethische Sprache der Schriftrollen mit der verwandter Literaturen und stellt seine Ergebnisse in den geschichtlichen Kontext. Im Zentrum seiner Untersuchung steht die Erforschung von vier miteinander verbundenen Grundfragen der Ethik in Qumran: Wie unterstützten schriftliche Traditionen die sektiererische

Moralkosmologie und die Halacha? Welchen Einfluss hatte die Ausbildung einer eigenen Identität auf Moral und Tugend? Wie erklären kulturelle und politische Kontexte den Einfluss anderer Ethiken in Qumran bzw. die sich wandelnde Einstellung zur Gewalt? Und schließlich: Inwieweit diente die Eschatologie als Motivation zur Moral? Marcus Tso wertet außerdem die

Forschung zum Thema aus und befasst sich dabei mit Themen wie Theonomie, Naturalismus, Dualismus, Determinismus und Rigorismus.

Marcus K.M. Tso Born 1965; 2000 MDiv, Regent College, Vancouver; 2009 PhD, University of Manchester; Adjunct Professor of Biblical Studies, Carey Theological College; since 2010, also Sessional Lecturer in Old Testament, Regent College.

\section{Jetzt bestellen:}

https://mohrsiebeck.com/buch/ethics-in-the-qumran-community-9783161516351?no_cache=1

order@mohrsiebeck.com

Telefon: +49 (0)7071-923-17

Telefax: +49 (0)7071-51104 